$\begin{array}{ll} & \text { Etnográfica } \\ \text { etnográfica } & \text { Revista do Centro em Rede de Investigação em }\end{array}$

Antropologia

vol. $25(2) \mid 2021$

Vol. $25(2)$

\title{
Memorias cercanas y memorias lejanas: de los relatos sobre la experiencia local de la violencia a la configuración de una narrativa conmemorativa en Colombia
}

Close and distant memories: from the stories about the local experience of violence to the configuration of a commemorative narrative in Colombia

\section{Gabriel Ruiz Romero}

\section{OpenEdition}

\section{Journals}

\section{Edición electrónica}

URL: https://journals.openedition.org/etnografica/9733

DOI: 10.4000/etnografica.9733

ISSN: 2182-2891

Editor

Centro em Rede de Investigação em Antropologia

Edición impresa

Paginación: 335-356

ISSN: 0873-6561

\section{Referencia electrónica}

Gabriel Ruiz Romero, «Memorias cercanas y memorias lejanas: de los relatos sobre la experiencia local de la violencia a la configuración de una narrativa conmemorativa en Colombia », Etnográfica [En línea], vol. 25 (2) | 2021, Publicado el 29 julio 2021, consultado el 19 enero 2022. URL: http:// journals.openedition.org/etnografica/9733 ; DOI: https://doi.org/10.4000/etnografica.9733

\section{(c) (i) (8)}

Etnográfica is licensed under a Creative Commons Attribution-NonCommercial 4.0 International License. 


\section{Memorias cercanas y memorias lejanas: de los relatos sobre la experiencia local de la violencia a la configuración de una narrativa conmemorativa en Colombia}

\section{Gabriel Ruiz Romero}

$\mathrm{Al}$ respecto, el texto afirma que los informes oficiales de memoria son necesariamente dispositivos narrativos distantes para los actores locales, de cuya memoria esos informes buscan ser reflejo. Se configura así una tensión entre las memorias cercanas locales que circulan dentro de las propias comunidades y las memorias lejanas conmemorativas que se dirigen hacia el espacio social y político externo donde tienen lugar las disputas por la memoria nacional. El artículo está basado en un trabajo de campo extenso realizado en las poblaciones palafitas de la Ciénaga Grande de Santa Marta, zona que en el año 2000 fue epicentro de dos masacres realizadas por ejércitos paramilitares de extrema derecha, dentro del contexto del conflicto armado colombiano.

PALABRAS CLAVE: memoria, informe de memoria, relatos, narrativa, conmemoración, conflicto armado colombiano.

Close and distant memories: from the stories about the local experience of violence to the configuration of a commemorative narrative in Colombia - In this regard, the paper states that the official reports of memory are perceived as distant narrative devices by the local actors whose memory these reports seek to reflect. A tension is thus established between the local close memories that circulate within the communities themselves and the distant commemorative memory that is directed toward the external social and political space where the disputes for the national memory take place. The article is based on an extensive fieldwork carried out in the pile dwelling populations of the Ciénaga Grande de Santa Marta, an area that was the epicenter of two massacres executed by right-wing paramilitary armies in 2000, within the context of the Colombian armed conflict.

KEYWORDS: memory, memory report, stories, narrative, commemoration, Colombian armed conflict.

ROMERO, Gabriel Ruiz (gruiz@udem.edu.co) - Universidad de Medellín, Facultad de Ciencias Sociales y Humanas, Colombia. 
A la memoria de Nancy Gutiérrrez, mujer entrañable que siempre me ofreció un hogar en Nueva Venecia.

"But should those who suffer bear, together with their pain, the burden of our collective memory?"

(Jackson 2002: 58)

\section{INTRODUCCIÓN: MARCOS DE INTERPRETACIÓN DE LA MEMORIA}

Es temprano en la mañana del 22 de noviembre del año 2017. En Nueva Venecia (Ciénaga Grande de Santa Marta, Caribe colombiano) está a punto de comenzar el acto conmemorativo de la masacre paramilitar ocurrida en el año 2000. A excepción de los estudiantes del colegio local, traídos aquí como parte de sus actividades escolares, son pocos los habitantes del poblado que han llegado a tiempo hasta el aula múltiple para atender la conmemoración. En la pequeña plaza ubicada al frente, lugar donde se cometió la masacre y único espacio de tierra firme en este poblado palafito, se ven unos hombres, bajo el sol, vertiendo arena sobre la plaza semi-inundada con el fin de tenerla a punto para los actos que allí se harán más tarde. En el aula, por su parte, son funcionarios del Centro Nacional de Memoria Histórica (CNMH) y de la Unidad para la Atención y Reparación Integral a las Víctimas de Colombia (UARIV) los que hacen esfuerzos por terminar los últimos preparativos para el acto conmemorativo. ${ }^{1}$

Son estos últimos quienes, una hora más tarde, dan inicio al mismo. La parafernalia de un acto oficial está en el orden del día. No es extraño, así, que sea el himno colombiano lo primero que se escuche. Desde el primer momento, la funcionaria que oficia como presentadora propone - y conduce ella misma - una conversación sobre el proceso de paz entre el Estado colombiano y las Fuerzas Armadas Revolucionarias de Colombia (FARC). El propio director regional de la UARIV utiliza su intervención de apertura del acto conmemorativo para hablar también sobre el proceso de paz. Cuando la presentadora retoma la palabra, invita a los chicos del colegio (ofreciéndoles, cómo no, una buena calificación a cambio) a que digan algunas palabras sobre los beneficios que traerá al país el proceso de paz con las FARC. Aquí, entonces, ya es preciso detenernos.

La masacre paramilitar por la que el acto estaba teniendo lugar no fue cometida por la guerrilla. Las Autodefensas Unidas de Colombia (AUC), sus

I El proceso de análisis de información y escritura de este artículo ha sido posible gracias a la Georg Forster Research Fellowship otorgada por la Alexander von Humboldt Stiftung en el año 2019. El autor agradece también al Lateinamerika-Institut de la Freie Universität Berlin por haber proporcionado el espacio de trabajo y discusión necesario para la construcción de este texto. 
perpetradores, eran una confederación de grupos armados de ultraderecha. Las FARC, por su parte, nunca hicieron presencia en los poblados palafitos de la Ciénaga Grande de Santa Marta. El frente 19 de esa agrupación guerrillera sí ejerció control territorial en el vecino departamento del César e incluso en zonas aledañas a la Ciénaga Grande, pero no sobre el agua, no en los palafitos. Otro grupo guerrillero, el Ejército de Liberación Nacional (ELN), sí tuvo un frente que operaba allí, el Domingo Barrios, que según los relatos locales tenía una base en las inmediaciones de la Ciénaga de la Aguja (que hace parte del complejo lagunar de la Ciénaga Grande de Santa Marta). ${ }^{2}$ Las FARC, entonces, no aparecen en los relatos locales como parte del entramado sociopolítico o como actor con alguna relevancia, precisamente por su inoperancia sobre el espejo de agua.

Pese a lo anterior, cualquier observador desprevenido que presenciara el acto conmemorativo podría pensar - estaría llevado a pensar - que se estaba conmemorando una masacre cometida por ese grupo guerrillero y por ello el sentido de enmarcar el acto como resultado del proceso de paz. La memoria no es solo del pasado, sino que es el presente de las cosas pasadas (Agustín 1984). Lo que el acto de conmemoración estaba evidenciando era el esfuerzo por enmarcar en una narrativa oficial presente (en este caso, la del proceso de paz con las FARC) el pasado de la guerra colombiana. ${ }^{3}$ Berthold Molden (2016) ha mostrado cómo el ejercicio político de construir hegemonía, en el sentido del término dado por Laclau y Mouffe (2001), es decir, en tanto la habilidad de los grupos socialmente dominantes de imponer su interpretación de la realidad, está basado en lo que él denomina "hegemonía mnemónica", a través de la cual se priorizan "unas formas de memoria sobre otras de acuerdo a específicas constelaciones de poder" (Molden 2016: 128). "Ganar la memoria [...] es fundamental en un proyecto político" (Semana, marzo 5 de 2019), dijo el ex candidato presidencial y senador de izquierda colombiano Gustavo Petro en el Congreso, hablando de la forma en que a su juicio un partido político opuesto buscaba construir una versión particular de la historia colombiana. Un acto

2 Las masacres paramilitares de Trojas de Cataca y de Nueva Venecia fueron justificadas, de hecho, por las AUC como "actos de guerra" contra "colaboradores y militantes" del ELN que habían realizado un secuestro masivo en la cercana Ciénaga del Torno en el año 1999 (Semana, octubre 7 de 2007). Sobre esta autolegitimación discursiva de las AUC, ver el trabajo de Castaño y Ruiz (2017).

3 Se trataba de un acto que tenía lugar en los últimos meses de gobierno del presidente Juan Manuel Santos (2012-2018), quien había hecho su principal apuesta política (incluso histórica) alrededor de ese proceso de paz. Por otro lado, si pasado aparece en cursiva es porque su empleo, para el caso del conflicto armado colombiano, no deja de ser problemático. La violencia en el marco de la guerra colombiana continúa en el presente, no sólo porque aún esté activo el ELN; también existen diversas organizaciones neo-paramilitares que surgieron después de la desmovilización de las AUC en el 2006 y nuevas disidencias que aparecieron después de la desmovilización de las FARC. De hecho, el número de asesinatos de líderes comunitarios y activistas sociales ha ido al alza desde la firma de los acuerdos (HRW 2018). 
conmemorativo es precisamente un escenario adecuado para ganar esa memoria, enmarcándola en un contexto particular.

Hablamos de marcos de memoria y pensamos de forma ineludible en Maurice Halbwachs (2004). Es, por supuesto, a él a quien debemos el concepto de marcos sociales de la memoria como elemento central sobre el cual se fundamenta su propuesta de la existencia de una memoria colectiva. En breve, su planteamiento es que los recuerdos, en tanto huellas individuales del pasado, solo devienen memoria cuando se enmarcan dentro de representaciones sociales de la realidad. Para nuestro propósito, nos resulta apropiado extender este concepto y hablar de marcos de interpretación de la memoria (y no ya de marcos narrativos, que son los que interesaban a Halbwachs).

Estos marcos de interpretación constituyen, por un lado, las representaciones sociales disponibles para insertar la memoria en una trama de sentido (Ruiz y Hristova 2019). Esto significa que la forma en que un ejercicio de memoria será recibido en una sociedad dada depende, en gran medida, de los valores (sociales, culturales, incluso morales) que prevalezcan en dicha sociedad. Por otro, además, los marcos de interpretación están determinados por la contingencia política del momento: "El pasado nunca actúa sobre una sociedad presente, sino que son las representaciones de eventos acaecidos las que son creadas, circulan y son recibidas dentro de un específico marco cultural y una realidad política determinada" (Assmann y Shortt 2012: 3). La creación, circulación e interpretación de una representación particular del pasado es lo que estaba teniendo lugar aquel 22 de noviembre de 2017, y lo que en general ha sucedido allí cada vez que se ha dado un acto conmemorativo por la masacre, o incluso cuando fuerzas del Estado han realizado en aquel lugar actos públicos de excusas oficiales por lo ocurrido (Ruiz 2017).

Este artículo busca, entonces, analizar la forma en que la construcción de una narrativa oficial pretende construir - o, al menos, fomentar - marcos de interpretación que posibiliten hacer de una memoria compartida una memoria conmemorada, que se correspondería así con lo que Ricœur (2013: 117) llama una "memoria obligada". El camino iría desde la memoria compartida que se hace colectiva, vía los marcos narrativos de Halbwachs, y luego deviene en memoria conmemorada, vía los marcos de interpretación que hemos mencionado. Lo que se analiza es cómo se configuran los relatos locales (aquí llamados memorias cercanas) y la forma en que la narrativa exógena (la memoria lejana) puede incluso rehacer el sentido de esas memorias cercanas para construir un régimen narrativo específico que busque delinear cierto contorno de la memoria.

El artículo es fruto de un trabajo de campo extenso realizado en las poblaciones palafitas de la Ciénaga Grande de Santa Marta (Caribe colombiano), en especial en Nueva Venecia. Dicho trabajo comenzó en el año 2010 y se prolonga hasta el presente. La longitud en el tiempo ha permitido estudiar 
distintos aspectos de procesos locales e institucionales relacionados con la masacre paramilitar que ocurrió en ese último poblado en el año 2000, en la cual 38 personas fueron asesinadas y gran parte de la población sobreviviente salió forzosamente desplazada. Las visitas de campo se han realizado al menos dos veces por año (exceptuando el año 2016, en el cual no se hizo visita alguna), atendiendo especialmente las fechas en las que tiene lugar algún tipo de interacción particular entre agentes del Estado y población local. Esto significa que las ceremonias de conmemoración de la masacre o los actos públicos de perdón por agentes del Estado han sido objeto de observación. Es entonces una variación de la etnografía multilocal (Marcus 1995), en la que se ha seguido a la trama y a los personajes, la que ha guiado el trabajo.

Hay que tener presente, al respecto, las consideraciones de Marc Augé (1998), en el sentido de que en sus trabajos de campo, el etnógrafo escucha y ve la representación de relatos. Esto significa, de cierta forma, que lo que observa son ya ficciones (en tanto composiciones) y no la verdad o incluso la realidad del tema analizado, asuntos estos que le resultan ajenos. Lo que se busca no es entonces aprehender la verdad del relato sino el sentido que tiene la propia composición de un relato particular y las razones por las cuales tal relato es compuesto de cierta forma. El centro de atención de este trabajo es, así, el proceso social de construcción del relato y no tanto el relato como producto acabado (Jackson 2002).

\section{LA MEMORIA CERCANA: EL RELATO}

"No me lo han contado

fue que yo mismo lo vi

el día que a Cataca fui

miré un pueblo desolado.

Todo estaba abandonado

se lo digo con franqueza

desde aquí la ausencia pesa

eso era lo que veía

en la pobre tierra mía

lo que hay es sucio y tristeza."

(Décima de Rafael Moreno) ${ }^{4}$

4 Bocas o Trojas de Cataca es el nombre de otro de los pueblos palafitos de la Ciénaga Grande. Allí, la noche del 10 de febrero del año 2000, varios hombres armados del bloque norte de las AUC encerraron a los habitantes del pequeño poblado y separaron a cuatro hombres, que serían asesinados antes de que los hombres armados abandonaran el pueblo. Este hecho, sumado al asesinato de otras seis personas en los días anteriores, provocó un desplazamiento masivo que ha hecho de ese pueblo, ubicado en la desembocadura del río Aracataca, un espacio apenas habitado por un puñado de familias en la actualidad. Rafael es uno de los que nunca regresó y desde su nueva casa, en la ciudad [continua] 
Dice Joan Didion (1979) que nos contamos historias a nosotros mismos para poder vivir. Michael Jackson lo pone en otros términos, unos que nos remiten con mayor precisión a las historias contadas por aquellos que han atravesado la experiencia del dolor producido por la violencia: "al construir y contar historias lo que hacemos es reelaborar la realidad para hacerla soportable" (Jackson 2002: 16). En estos casos, el acto de contar (y contarse a sí mismos) historias sobre la propia experiencia posibilita reconfigurar unas vivencias personales del dolor - que son en parte inefables - en expresiones que puedan ser compartidas entre aquellos que fueron afectados de forma similar por la violencia.

Se trata, en este primer nivel, de la elaboración de relatos sobre la experiencia violenta y las transformaciones que ella produjo en la vida - y en el grupo social - del relator. Son relatos en el sentido de ser ejercicios locales - normalmente en un registro oral - que dan cuenta de sucesos o eventos que giran en torno al eje del impacto de la violencia, sin abordar necesariamente ninguna tarea de contextualización de esos eventos (Cobb 2016), ni de búsqueda y análisis del sentido de la violencia ejercida. El relato es el que asume la fórmula enunciada por Elaine Scarry (1985): se centran en la descripción del arma y de la herida. Es, por ello, producto del trabajo de las memorias cercanas, esas que nacen y se ejercitan a nivel local, alimentadas por las historias de aquellos que fueron víctimas de la experiencia violenta. Es así como las memorias cercanas le hablan, de forma directa y hasta cierto punto desafiante, a aquellos que puedan reconocer la misma arma como la productora de una herida similar en sí mismos.

La fuerza de estas memorias cercanas está determinada por el hecho de dar cuenta de lo más privado (el sufrimiento ocasionado por la violencia) a través de instrumentos idiosincráticos que pueden, por tanto, ser reconocidos y compartidos localmente. En la región de la Ciénaga Grande de Santa Marta la décima es el arte depositario de la memoria colectiva, en tanto memoria comunicativa, como la entiende Jan Assmann (2008). Se trata, así, de una práctica social a través de la cual se refuerza la identidad común que, a su vez, está fundada en la experiencia local compartida del tiempo y en el desarrollo constante de prácticas y roles sociales fácilmente reconocibles por los miembros de la misma sociedad. Se trata de composiciones poéticas organizadas en estructuras de diez versos. Las décimas son entonadas por los pescadores en sus faenas de trabajo cotidianas, recitadas por hombres y mujeres en reuniones

[continuación] de Ciénaga, compuso numerosas décimas sobre el acto violento y la situación de los desplazados hasta su muerte (por causas naturales) en el año 2013. Por otro lado, por respeto al conocimiento y a las formas de expresión locales, todas las décimas y fragmentos de entrevistas aquí reproducidos se han dejado tal cual como han sido expresados originalmente, sin atender a correcciones ni a señalamientos de posibles errores gramaticales en su forma. 
comunitarias, o cantadas en parrandas sociales locales. Sus autores son decimeros y decimeras que se dedican día tras día a labores similares a las de sus coterráneos, pero que destinan, además, parte de su tiempo a la composición de versos. Éstos suelen dar cuenta de distintos aspectos de la vida diaria (los amores, las faenas cotidianas de trabajo, el deterioro ambiental de la Ciénaga Grande) o pueden relatar hechos que han marcado con fuerza la vida de la comunidad. En el caso de Nueva Venecia y de Bocas de Aracataca, las masacres paramilitares que allí ocurrieron y el desplazamiento forzado que ellas produjeron han sido el tema de diversas composiciones de este tipo.

Rafael Moreno, uno de esos decimeros conocidos en la zona, tenía precisamente un cuaderno lleno de décimas compuestas por él sobre la masacre en Cataca y la vida de desplazamiento forzado en la población de Ciénaga. Se trata de relatos en verso sobre la experiencia vivida, en los que suele reiterarse lo que la violencia se llevó (la descripción de la herida, en la estructura de Scarry) pero sin haber en ellos un intento de rastreo de las causas de esa violencia o del lugar que el hecho concreto ocupa en las dinámicas del conflicto armado colombiano. Lo que los versos contienen es el relato de unas ausencias:

"Voy a hacer un referido de mi pueblo cataquero

Por cierto once de febrero todo allí quedó perdido

El pueblo despavorido no creía que fuera cierto

Que todo quedó desierto al amanecer del día

Porque allí nadie creía de que hubieran tantos muertos

Diré del niño Moreno, un hombre tan servicial

Y sobre todo leal, cariñoso, honrado y bueno

Que lo cuide el Nazareno y lo tenga bien seguro

Eso sí se lo aseguro, pasando este trago amargo

Pedro Pacheco Camargo, lo acompañó su hijo Arturo

Al formarse la trifulca allí nadie lo creía

Que al amanecer del día hubiera muerto la Turca

Eso fue cosa maluca y para nadie es extraño

Sin sufrir ningún engaño y esto nadie me lo cree

Que desde el mismo día diez ya venían haciendo daño

Les diré de Emer Cantillo, también su hermano Pedrito

También diré del loquito Luis Carlos por lo sencillo

Y aquí en este estribillo yo quiero envolver a Abel

Con un ramo de clavel, marido de Tomasita

Se quedó la pobrecita embarazada de él."

Versos similares entona la familia Manga, una familia de músicos de Nueva Venecia muy conocidos en el área de la Ciénaga Grande. En parrandas a las que son invitados o en actos públicos en los que participan suelen cantar, entre 
otras cosas, algunas composiciones sobre la masacre de Nueva Venecia, basadas en décimas compuestas por Olga Viola, una mujer que nació y vivió por muchos años en el poblado palafito. Ella, como Rafael para el caso de Bocas de Cataca, tiene también un cuaderno lleno de versos manuscritos sobre lo sucedido en Nueva Venecia. La versión de uno de ellos, la que más repiten los Manga en sus composiciones, da cuenta también de las ausencias que la violencia produjo:

"El caso que ocurrió en Nueva Venecia deja cultivado muchos dolores

Por la muerte de humildes pescadores que quedaron tendidos allá en la iglesia Nueva Venecia, pueblo querido, iay qué tristeza pasó contigo!

Mataron a Martín y Octavito, hermanitos que botes componían También mataron a Armando Mejía, acabaron con la vida de Basilito iAy Erasmito, ay Erasmito! iAy Erasmito que murió a los pocos días! En mi pueblo nunca olvidarán la tragedia la noche del quejido Por la cruel muerte de Kalimán, el difundo Murcia y a Darío Amigos míos, amigos míos, amigos míos que hoy en las tumbas están.”

Los ausentes nombrados en los versos ("la Turca", el "loquito Luis Carlos", el "niño Moreno", "Martín y Octavito", "Erasmito") no precisan de apellidos o mayores señas de identificación, por tratarse de personajes conocidos localmente. Así, el relato está dirigido en primer lugar a aquellos que puede reconocer a esos ausentes apenas nombrados. Para el caso de Trojas de Cataca esto representa un hecho aún más relevante pues en las narrativas oficiales conmemorativas sobre el hecho (de las que nos ocuparemos en el siguiente apartado) no se mencionan las identidades de las víctimas o incluso se dice de forma textual que "se desconoce" el nombre de éstas (CNMH 2014; Rutas del Conflicto s.f.). Pero no se trata, en absoluto, de desconocidos: ellos tenían un lugar en la cotidianidad local: éste era un hombre "servicial", "cariñoso, honrado y bueno"; aquel era el "loquito" del pueblo; el de más allá era el "marido de Tomasita"; y esos de allí los que "botes componían". Ocupaban un lugar en el entramado diario que después de la violencia quedó vacío. Es ese vacío, esa ausencia, la que es relatada en las memorias cercanas. La herida es descrita en términos de algo que ya no está allí.

"No se necesita echarle carbón a la gente para que recuerde a sus víctimas", dice un viejo habitante de Nueva Venecia [entrevista personal, noviembre 22 de 2018, Nueva Venecia, Magdalena, Colombia] con respecto al hecho de que las personas de su pueblo recuerdan lo acontecido, y en especial a sus seres queridos, sin necesidad de que organismos externos promuevan o pidan la activación de esas memorias. Los repertorios idiosincráticos locales mantienen en ejecución un "modelo performativo" de las memorias (Jackson 2005) en el que éstas hacen su aparición social entre pares comunitarios. El término 
performativo tiene aquí, por tanto, no sólo el sentido que le otorga Judith Butler (2017), en tanto ejecución corporal para ampliar (incluso crear) el espacio de aparición política (el espacio donde los intereses y necesidades privados se hacen públicos), sino entendido como un espacio de aparición social de la memoria.

Con esto último nos referimos al hecho de que a través de los repertorios de las memorias cercanas la propia víctima puede lograr imaginar que es parte de una red local afectiva y de sentido en la cual sus propias acciones, y también sus propios recuerdos, cuentan y son importantes (Jackson 2002). Esto constituye una forma de poder reconocerse como parte de los otros cercanos, los que Ricœur (2013) llama los allegados, aquellos que cuentan para nosotros y para los que nosotros también contamos. Los relatos construidos y compartidos (contados y representados) construyen vínculos intersubjetivos de pertenencia a un mismo lugar. No hablamos de un lugar físico y ni siquiera un lugar necesariamente real, sino uno creado y recreado, esto es, imaginado, a través del propio acto de relatar. El pasado común no es así lo que pasó sino el pasado que ha sido representado a través de esos relatos locales. Es en este sentido que Michael Jackson (2002) afirma que reconstruir los eventos en una historia no es elaborarlos pasivamente, sino vivirlos de forma activa, tanto en diálogo con los otros como con la propia imaginación sobre esos eventos.

Las memorias cercanas hacen frente así a uno de los efectos devastadores que la violencia tiene sobre sus víctimas: el de haber sido anulados en tanto sujetos de derecho y haber sido sometidos a la experiencia límite de sentir que su bienestar y su propia vida no contaban para nadie. La expresión máxima de esto es la que Giorgio Agamben (2010) ha descrito como "nuda vida", la reducción del sentido de la vida a sus funciones biológicas. Pero aún sin llegar al hundimiento propio del musulmán en el campo de exterminio, tan bien descrito por Primo Levi (2014), lo que la violencia se lleva (o busca llevarse) es, en este sentido, la posibilidad de imaginar que existen personas para las que contamos. ${ }^{5}$ En su lugar, la violencia instala la indiferencia o el desprecio ejercido por otros para los cuales no contamos ni como sujetos de aprecio ni en tanto sujetos de derecho.

Las memorias cercanas operan, en este sentido, en tanto vasos comunicantes con aquellos quienes poseen también el conocimiento dado por la experiencia límite de la exclusión. El relato de las memorias cercanas es así, en primer lugar, el espacio de la transmisión de ese conocimiento a quienes tienen la autoridad para recibirlo, a los allegados que también pueden reconocer

5 Según Levi y otros sobrevivientes de los campos de exterminio Nazi, el musulmán era la forma en que era llamada allí la persona que tocaba fondo, aquella que, en palabras de Manuel Reyes Mate (2003), ya había bebido de forma íntegra del cáliz del sufrimiento y por tanto estaba hundido de forma definitiva. 
- y reconocerse - en la herida que el relato describe. Es por esto que las memorias cercanas, en tanto espacio construido entre todos, operan como manifestación social local de que los sobrevivientes no sólo sobrevivieron físicamente, sino - y quizá de forma primordial - socialmente: "sin historias, sin escucharse mutuamente las historias, no puede haber recuperación de lo social, no puede haber descubrimiento de un espacio o una causa común" (Jackson 2002: 104).

En espacios marginales, como suelen ser los lugares donde más ha impactado la violencia armada colombiana, lugares en los que ya existía - y existe una violencia estructural profunda (GMH 2013), encontrar causas comunes, o incluso reconocer el espacio como un espacio común, no es tarea fácil. El espacio social suele estar cooptado allí por sujetos e instituciones no interesados en desarrollar proyectos políticos que originen beneficios sociales, sino interesados en la obtención de réditos para sí en el corto o mediano plazo. Frente al estado de precariedad social circundante, las memorias cercanas son una forma - débil, es cierto, pero necesaria - de reclamar el espacio como propio y mantener activa la imaginación de la existencia de lo común. El hecho de que esas memorias sean una construcción conjunta contribuye a ello. No es entonces que las memorias cercanas estén más próximas a la verdad de lo sucedido. No es ese su valor social local. La importancia que éstas tienen es la contribución que realizan a la construcción de un presente común y, por tanto, de un sujeto social común que puede reconocerse en los relatos que se comparten.

Las memorias cercanas permiten, a los individuos que las producen y las reproducen, poderse situar en una posición con relación a sus allegados y con relación a ellos mismos dentro del presente de su comunidad (White 2000). Ahora, los relatos que constituyen las memorias cercanas no son fijos. Son contados una y otra vez, no sólo por decimeros o cantantes locales para el caso de los pueblos palafitos de la Ciénaga Grande de Santa Marta, sino potencialmente por cualquier habitante del lugar. Al volver a ser referido, el relato se reproduce, esto es, se transforma. No sólo los Manga cantan su versión de los versos de Olga Viola. Cada quien, cuando hace memoria al conversar con sus vecinos o en los muchos momentos en que alguien de afuera (un funcionario, un investigador) pide un recuento de lo ocurrido, emplea esta o aquella manifestación de las memorias locales, este o aquel relato, para complementar y ampliar, el suyo propio.

Las memorias locales se intra-alimentan entre sí. En efecto, cuando alguien recuerda y empieza a relatar lo recordado, ese relato ya está nutrido de los repertorios locales de memoria con los que se ha estado en contacto. Es a esto a lo que se refiere Cornelia Soravji (2006) cuando explica, para el caso de Bosnia, que no es que las nuevas generaciones tengan la misma memoria sobre los hechos traumáticos del pasado que la que tienen sus padres, sino que las dos comparten un almacén (store) de imágenes y emociones que cada quien emplea para construir su propia memoria. Los relatos vividos se vuelven 
relatos contados (que alimentan el "archivo" local) y en algún punto unos y otros se confunden en las memorias cercanas.

Estas memorias, entonces, se producen y reproducen así en ese "espacio potencial" que existe entre los individuos y su entorno (Winnicott 1974), esto es, en un espacio donde no hay separación entre lo individual y lo colectivo, sino que el relato común del pasado se ofrece a la memoria individual, contribuyendo a la construcción local de un universo simbólico común. Se trata entonces de la memoria como reconocimiento, en un sentido que hace eco de la forma en que Ricœur (2013) emplea este término, siendo aquí un reconocimiento en tanto la aprehensión común (o comunitaria) del recuerdo y su instalación en el contexto social presente.

Las memorias cercanas fundamentan su autoridad en el cumplimiento de la fórmula-tipo del testimonio, tal y como ésta es expuesta por Paul Ricœur (2013: 21 1): “yo-estaba-allí". "No me lo han contado/fue que yo mismo lo vi". Así comienza la décima de Rafael. Pero añade Ricœur (2013) que quien así atestigua pide, además, ser creído, esto es, certificado por otros. Es ese aspecto fiduciario del relato en el que aparece otro tipo de memoria, la memoria lejana, en tanto acreditación de las memorias cercanas y por esa vía, en su eventual transformación en memoria conmemorada.

\section{LA MEMORIA LEJANA: LA NARRATIVA}

El modelo performativo que analiza Jackson (2005) se fundamenta en lo que él denomina una "relación complementaria" entre las diferentes voces que construyen el relato. La existencia de esta relación implica "que cualquier individuo puede, si [durante el intercambio de relatos] tiene lugar un empleo injusto de algún privilegio o poder, tomar medidas para realinear y reafirmar el orden social" (Jackson 2005: 359; énfasis en el original). Se trata de una complementariedad no orientada a la imposición de un consenso, sino al sostenimiento del acto de relatar como una acción compartida en la cual las experiencias privadas se vuelven parte de las (micro)políticas de la vida cotidiana, alcanzando significados nuevos que puedan adecuarse a la realidad actual del grupo (White 2000). No hay entonces una voz autorizada para cerrar el relato - para imponer su versión - sino que aquel debe mantenerse abierto a una constante reconstrucción y resignificación.

Pero sucede que la frecuencia y la espontaneidad con la que surgen los relatos va disminuyendo con el paso del tiempo. Soravji (2006) ha expuesto que a medida que el fin de la guerra en los Balcanes iba quedando temporalmente atrás, los relatos sobre lo allí acontecido no sólo eran menos frecuentes, sino que tendían a asumir una forma más organizada, más estructurada narrativamente - más estereotipada podríamos decir - comparada con la de los relatos que se hacían justo después de la guerra. Para el caso de Nueva Venecia, no 
es que las historias sobre lo sucedido en el año 2000 hayan dejado de contarse. Esos relatos siguen estando presentes con cierta frecuencia, en especial en fechas conmemorativas. Pero lo que ha ido desapareciendo es la espontaneidad del contexto en el que se dan.

Los relatos locales, en especial después del gran acto conmemorativo que tuvo lugar en el palafito en el décimo aniversario de la masacre (en el que hubo un gran despliegue institucional), han seguido reproduciéndose más como respuesta a la demanda de ellos por parte de diferentes agentes externos que a través de las propias dinámicas internas. Representantes del Estado, colectivos de abogados, colaboradores de ONG, cooperantes internacionales, investigadores académicos, todos hemos hecho presencia en el poblado casi de forma permanente desde entonces. Muchos de estos agentes realizan solicitudes constantes de los relatos sobre la masacre paramilitar. Esto es particularmente cierto para el caso de agentes institucionales, como representantes de la UARIV, investigadores del CNMH, agentes de la Fiscalía General de la Nación, o funcionarios de la alcaldía municipal o de la gobernación departamental encargados de gestionar programas de reparaciones individuales o colectivas.

Esta demanda del ejercicio de la memoria ha llegado, incluso, a percibirse como abrumadora por parte de los residentes. La expresión, referida antes, según la cual no se necesita carbón para alimentar la memoria local, fue expresada, en principio, como descontento frente a ese constante reclamo externo de memoria. Por su parte, una mujer de la localidad que en su momento tuvo que desplazarse forzosamente debido a la masacre y por cuya casa desfilan muchos funcionarios e investigadores en busca de alojamiento - y de contactos locales -, lo expresa sin emplear metáfora alguna: "La primera vez que oí hablar de memoria fue con la Unidad de Víctimas. Pero ya estamos como tan saturados del tema que ya como que queremos hacer otra cosa" [entrevista personal, noviembre 21 de 2018, Nueva Venecia, Magdalena, Colombia].

Si la sociedad es el espacio donde los intereses privados adquieren significado público (Arendt 2016), el relato puede ser entonces un instrumento mediante el cual la experiencia privada del dolor, al hacerse pública, deviene práctica social, incluso política. Es en este sentido que Sara Cobb afirma que cuando las personas son separadas de la posibilidad de contar sus propias experiencias, aquellas dejan de tener "acceso a la producción del significado y, por ende, ni la protesta ni la política son posibles" (Cobb 2016: 52). Pero lo que puede estar sucediendo con el reclamo externo del ejercicio de memoria es que paradójicamente esté contribuyendo a separar a las personas de sus propios relatos, de sus memorias cercanas.

Para analizar esta posibilidad, nos resulta útil, primero, diferenciar entre relato y narrativa. Al hablar de relato, como lo hemos hecho al estudiar las memorias cercanas, lo entendemos como una serie de eventos puntuales, contados desde una perspectiva personal - o empleando el almacén de memoria 
local que señalamos antes -, más o menos encadenados dentro de una historia. No hay en el relato un intento de contextualizar esos eventos en una narrativa más amplia que posibilite darle un sentido a la violencia padecida (Cobb 2016). Es por ello que la estructura arma-herida lo define muy bien: es en la mención o descripción de estos dos elementos en la que el relato se agota. Una narrativa, por su parte, requiere una contextualización y exige también unas líneas explicativas sobre las tramas de la violencia. Para el caso de los pueblos palafitos de la Ciénaga Grande, las líneas explicativas narrativas se precisan para enlazar las masacres allí ocurridas, en primer lugar, dentro de la lógica de tierra arrasada de la violencia paramilitar, y, en un sentido más amplio, dentro de las dinámicas del conflicto armado colombiano o incluso de violencia estructural del país.

Empleando los términos ya clásicos de Ricœur (2004 [1995]), podríamos decir entonces que el relato se instala en la Mímesis I (el antes de la narración, la preconfiguración) y que la narrativa coincide con la Mímesis II (la configuración), en cuanto es allí donde tiene lugar una disposición particular de los hechos que constituye la construcción de la trama. La narrativa es, en este sentido, ya un ejercicio de interpretación. Lo que ella hace es universalizar el relato, esto es, buscar vínculos de causalidad entre acontecimientos singulares. Es la ordenación de la trama y la búsqueda de un sentido narrativo la que le otorga a dicha trama su universalidad: "Componer la trama es ya hacer surgir lo inteligible de lo accidental, lo universal de lo singular, lo necesario o lo verosímil de lo episódico" (Ricœur 2004 [1995]: 96).

Los relatos cercanos, como lo expusimos arriba, son una forma que tienen las comunidades locales de recuperar el sentido compartido de la vida cotidiana, una forma de tratar de responder conjuntamente a la cuestión fundamental del quiénes somos ahora, que se plantea en el proceso de confrontación de los efectos de la violencia. Nos encontramos de nuevo con una manifestación de memoria comunicativa (Assmann 2008). Son formas no institucionalizadas de rememoración que sirven para construir o reforzar la identidad comunitaria a través del devenir cotidiano. Aunque pueden adquirir cierta forma convencional (como en el caso de las décimas que señalamos antes), el hecho de operar dentro de una relación complementaria, hace que dicha convencionalidad sea lo suficientemente flexible para ser remoldeada de forma constante, sin representar ello ningún tipo de transgresión cultural.

Pero ¿qqué sucede entonces, a nivel local, cuando el Estado, en nombre del deber de la memoria, reclama esos relatos para verterlos en una narrativa de sentido cuyo modelo-tipo es un informe de memoria? Al tratar de dar un sentido global a la experiencia local de la violencia, la narrativa busca transformar experiencias y emociones locales sobre el pasado violento en artefactos públicos de memoria que puedan moverse en un espacio social y político que trascienda lo local, con el objetivo de contribuir a la reparación simbólica de las 
víctimas de una violencia pasada. Es esto, grosso modo, lo que se conoce como el deber de la memoria y del cual el informe de memoria es un instrumento central. ${ }^{6}$ El informe de memoria se sitúa, así, en el intersticio que queda entre la memoria comunicativa local y la memoria cultural, entendida esta última como aquella reificada en monumentos, museos y, en último término, en la historia (Assmann 2008).

Pero se trata de un ejercicio de memoria lejana, no sólo porque la traducción de los relatos locales a un registro escrito formal los separa de cierta forma del almacén de imágenes y de emociones locales de memoria, sino porque su proyección es hacia el afuera de la propia comunidad. En efecto, el trabajo de una entidad como el Centro Nacional de Memoria Histórica, institución pública que en Colombia tiene la función de documentar las violaciones a los derechos humanos ocurridas con ocasión del conflicto armado colombiano (Presidencia de la República de Colombia, art. 2, decreto 4803 de 2011), está orientado a "contribuir a la realización de la reparación integral y el derecho a la verdad del que son titulares las víctimas y la sociedad en su conjunto, así como al deber de memoria del Estado" (CNMH 2017). El trabajo de una institución de esta índole enlaza entonces las experiencias de violencia de las comunidades locales - y su derecho a la verdad en tanto medida de reparación - con el deber del Estado de dar a conocer esa verdad al resto de la sociedad. La "sociedad en su conjunto" es entonces el espacio social final al que aspira a llegar el trabajo institucional de la memoria.

Pero el propio CNMH, por su parte, hace énfasis en que su labor está dirigida, en primer lugar, a las comunidades víctimas. Por ejemplo, en el informe presentado sobre Bojayá (GMH 2010), cuando se señala las disputas por la memoria sobre lo sucedido que han tenido lugar entre el Estado y otras fuerzas sociales y políticas, se afirma que el problema está en las memorias que han sido "construidas desde fuera de la comunidad y dirigidas no tanto para las víctimas locales como para un público nacional e internacional" (GMH 2010: 20). ${ }^{7}$ A diferencia de ello, el texto señala a continuación que él es reproductor de la lectura del hecho "construida por los habitantes de Bojayá" (GMH 2010: 20). La misma constatación puede encontrarse básicamente en todos los informes del CNMH. El realizado sobre lo sucedido en las poblaciones palafitas de la Ciénaga Grande de Santa Marta no es la excepción:

6 El hecho de que la memoria haya devenido en un deber de los Estados tiene, por sí mismo, sus problemas, no sólo en el orden político sino incluso epistemológico. Para una discusión sobre ello, ver Augé (1998) y Todorov (2013).

7 Bojayá es un poblado a orillas del río Atrato, en el departamento del Chocó, cerca de la costa Pacífica colombiana. Allí 79 personas murieron asesinadas debido a la explosión de un cilindro de gas arrojado por la guerrilla de las FARC en medio de combates con las AUC. El cilindro cayó en la iglesia donde más de 200 personas se refugiaban, produciendo así uno de los mayores casos de victimización fatal que ha tenido lugar en el contexto de la guerra colombiana. 
"Estos aspectos [el contenido del informe] son desarrollados con base en los testimonios de las víctimas: el recuento de lo sucedido parte de las voces locales de los protagonistas y sobrevivientes del siniestro, para mostrar la magnitud del conflicto armado desde la experiencia personal" (CNMH 2014: 19).

No hay duda de que, en efecto, el trabajo institucional de la memoria llevado a cabo por una entidad como el CNMH (y, en general, también por otras instituciones o investigadores académicos) parte de la recolección de las "voces locales". Los investigadores se desplazan al terreno varios días (incluso semanas) y allí recogen la información primaria directamente de las personas que viven en la comunidad y/o que vivieron la experiencia violenta que se está buscando narrar. No hay duda, tampoco, de que la intención de la mayoría de trabajos de este tipo es la de contribución a procesos locales de reparación simbólica. Pero no es ello el objeto de nuestra discusión aquí. Lo que buscamos señalar es que la narrativa que construye un informe de memoria (o incluso un artículo académico, como este mismo) se enmarca en una "condición paradójica [...] que limita su horizonte discursivo" (Jurado, Castaño y Ruiz 2018). ${ }^{8}$ Estas narrativas no son lejanas porque los productores de las mismas se sitúen lejos de las experiencias locales, sino porque el propio espacio de producción y circulación de ellas las separa epistemológicamente de los relatos locales.

Dijimos antes que las narrativas buscan transformar las experiencias locales en artefactos públicos de memoria. El modelo-tipo de tales artefactos es el informe de memoria (o el artículo científico). Se trata de textos construidos con un lenguaje propio de instituciones o individuos que hacen parte de sistemas expertos, es decir, de sistemas "de experiencia profesional que organizan grandes áreas del entorno material y social en el que vivimos" (Giddens 201 1: 37). Los sistemas expertos producen, por su propia naturaleza, un conocimiento propio de una racionalidad moderna. Esto determina a priori (independiente de la calidad de esta o aquella narrativa particular) un distanciamiento no contingente sino necesario entre ella y los relatos locales de los cuales pretende ser eco.

Esta distancia determinada por las condiciones de producción de la narrativa tiende a ampliarse con el proceso de circulación de la misma. Como se ve en la figura 1, mientras las memorias cercanas consisten en relatos de reconocimiento cuyo sentido es la (re)producción en el microcosmos local para darle sentido al presente comunitario, la narrativa es una producción cuyo objetivo final es su proyección hacia el macrocosmos externo, hacia el afuera donde tienen lugar las disputas por la memoria. En ese espacio, lo que está en juego no 
Macrocosmos: las disputas de la memoria

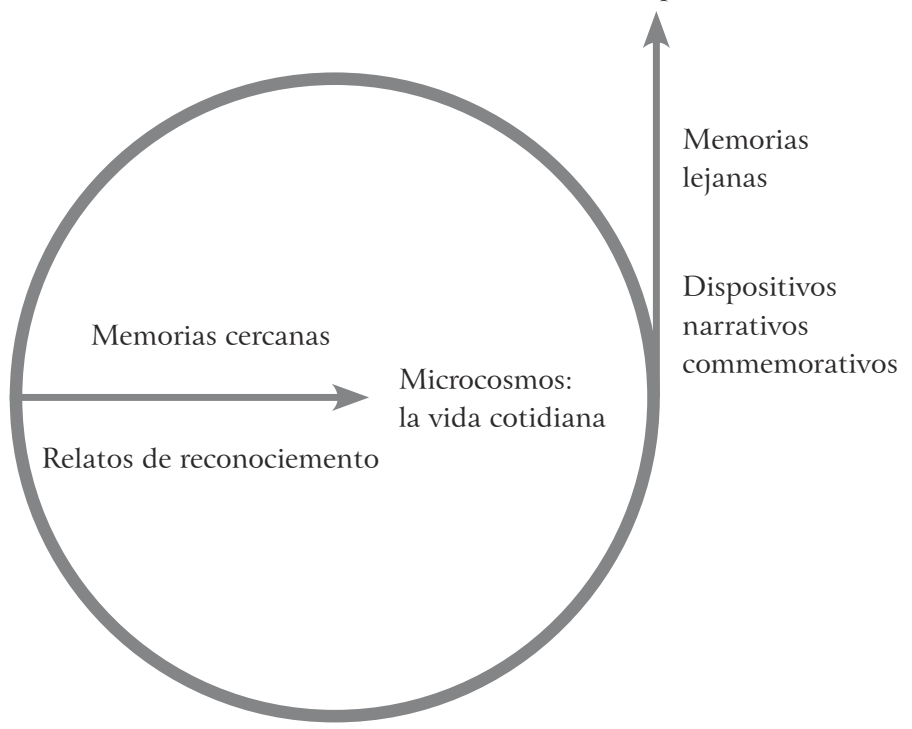

Figura 1 - Memorias cercanas y memorias lejanas. Fuente: Elaboración propia.

es el presente (de una comunidad) sino el futuro (de la nación o de cualquier comunidad imaginada de este tipo). Se trata, en este sentido, de un ejercicio conmemorativo de la memoria lejana.

Si hablamos de una memoria lejana conmemorativa es porque mientras los relatos constituyen lo que con Ricour (2004 [1995]) podríamos denominar configuraciones dinámicas del tiempo (el tiempo local que fluye a través de la vida cotidiana), la narrativa es una configuración fija del tiempo (el tiempo histórico que busca hacerse memoria de la nación). Se trata de una configuración fija porque a diferencia de los relatos que se transforman con el tiempo al ser recontados, la narrativa queda fijada en el texto escrito. Al quedar así establecida y ordenada en un dispositivo de memoria como lo es un informe, la narrativa conforma una forma de memoria conmemorativa adecuada al contexto político (incluso a la sensibilidad social misma) del momento en que se elabora.

La narrativa queda así expuesta a dinámicas y juegos de poder que son ajenos a la comunidad local e incluso pueden serles inconvenientes. ${ }^{9}$ La memoria

9 Para ejemplificar esto, podríamos pensar en el reciente nombramiento (febrero 2019) del nuevo director del CNMH. La persona que fue nombrada por el presidente colombiano en ese cargo es un académico que ha defendido públicamente una posición negacionista en relación con la guerra en el país. Haciendo juego al discurso de la derecha colombiana, esta persona ha dicho que en Colombia no ha habido un conflicto armado sino una amenaza terrorista confrontada por el Estado. También ha manifestado en público su animadversión contra cualquier representante de la izquierda política [continua] 
lejana, en tanto artefacto conmemorativo, sirve - incluso a su pesar - para construir un pasado representativo de la nación que puede ser empleado para proyectar un futuro deseado. Es por esto que las disputas por la memoria no son, en un sentido último, disputas por el pasado propiamente dicho (por la verdad de ese pasado), sino disputas en el presente por una posición privilegiada desde la cual producir o promover un régimen de verdad particular (Ruiz y Hristova 2019).

Ahora, el propio dispositivo-tipo de la memoria lejana, el informe escrito, la separa de las poblaciones cuyas voces hacen eco. En Colombia, las víctimas del conflicto armado pertenecen en gran número a un sector poblacional que ha padecido también una violencia estructural de largo tiempo (GMH 2013). Se trata de poblaciones en su mayoría rurales, cuyo acceso al sistema educativo colombiano ha sido mínimo (cifras del Ministerio de Educación Nacional reflejan que sólo un 25\% de la población rural llega a la educación media - no necesariamente la termina - y únicamente un $1 \%$ accede a la educación universitaria). El libro no es, por tanto, un objeto habitual en sus dinámicas. Quien, para el caso de Nueva Venecia, busque una casa donde haya una biblioteca, habrá emprendido una pesquisa infructuosa:

“[...] aquí, recuerdas tú que en la ceremonia que se hizo [en el aniversario 14 de la masacre] se repartió el libro [el informe]. Pero recuerdas tú que este tipo de comunidades, que es la oralidad la que hace base de ella. La letra poco nos importa, ¿ya? Entonces la letra no vale mucho sino lo que...

¿Tú crees que aquí son muy poquitos los que lo han leído [el informe]?

Sí, muy poquitos. Es que la gente no tiene... prácticamente nosotros estamos de lectura malos, mal de lectura.

¿Y tú leíste el informe?

Sí, yo leí el informe.

¿Y qué te pareció?

Para mí el informe me pareció que mucha literatura.

¿Mucha literatura? ¿Cómo así?

Un documento más que... para mí es literario [...]. Se trató lo convencional, lo que la gente habla, los eventos, lo que pasó, se cita a unos perpetradores que dudo yo que ellos hayan hecho parte de esa masacre. Por lo menos hay un cuento que me acuerdo que cogieron con un garfio, con un gancho de esos de carne que... que eso es literatura, eso no pasó." [Conversación con un viejo habitante del palafito, enero 15 de 2017, Nueva Venecia, Magdalena, Colombia]. dicionan los ejercicios de las memorias lejanas escapan a cualquier dominio de las poblaciones locales en las que, en teoría, se basa dicho trabajo. 
Este hombre es, de hecho, una excepción. Encontrar en Nueva Venecia a alguien que haya leído el informe - o incluso que sepa de su existencia - no es tarea fácil: "nunca había visto ese informe mijo. Yo que me la paso de casa en casa aquí y nadie me ha hablado de él ni nunca lo he visto en ninguna casa. Y yo que sí me camino todo el pueblo" [promotora de salud, entrevista personal, noviembre 22 de 2018, Nueva Venecia, Magdalena, Colombia]. Tampoco las personas de la localidad que hacen parte de un comité de impulso de medidas de reparación colectiva (conformado por iniciativa de la UARIV, en cumplimiento de su mandato legal) lo han leído, ni siquiera el apartado donde se hacen recomendaciones para la reparación: "Nosotros nunca usamos ese informe. Pa' que te voy a echar mentiras" [mujer que hace parte del comité local de impulso, entrevista personal, noviembre 21 de 2018, Nueva Venecia, Magdalena, Colombia].

Por otra parte, aquellos pocos que sí han leído el informe no logran ver reflejadas sus voces completamente en él. Hablando con un hombre cuyo suegro fue asesinado durante la masacre de Nueva Venecia, decía con molestia: "yo lo leí un poquito y te digo la verdad, tiene un poquito de exageración. Eso tiene un montón de embustes: y que los perros se comían los cadáveres. ¡Eso es falso! iJoda!, yo leí ese pedacito y vi eso y me dio fue rabia." [Hombre familiar de víctima fatal de la masacre paramilitar, noviembre 21 de 2018, Nueva Venecia, Magdalena, Colombia]. Otro más, cuya hija leyó “por encimita" el informe, comenta sobre el mismo episodio del garfio referido antes: "[...] entonces ahí dicen que un paramilitar, que se pone a hablar de un tal gancho [con el que supuestamente colgaron a algunas de las víctimas], que el gancho de cocina, que lo utilizamos para no sé qué [...] no, hay como tres historias raras" [pescador, entrevista personal, noviembre 21 de 2018, Nueva Venecia, Magdalena, Colombia].

La mención de los perros y del gancho aparece en el informe bajo el subtítulo "la masacre de Nueva Venecia en versión de un paramilitar". No hay referencia a la fuente de donde se tomó el testimonio de este hombre, identificado como un "desmovilizado del bloque norte" (CNMH 2014: 123). El testimonio sirve en el informe como base para una discusión analítica sobre las particularidades de la devastación que produce el empleo de una masacre como "acto bélico" (CNMH 2014: 126). Un fragmento de este tipo, producto del testimonio de un victimario y cuya presencia en un informe de memoria (más allá del error de la falta de citación adecuada del mismo) sea quizá necesaria para poder indagar en las dinámicas y sentidos de la violencia ejercida, resulta molesto - incluso ofensivo - para los pobladores locales. En especial éste cuya transcripción comienza diciendo "una masacre no se comete sin una causa justa” (CNMH 2014: 122). Los habitantes locales no tienen - y no tienen por qué tener - el conocimiento experto para interpretar un fragmento así como pieza necesaria dentro de una estructura analítica compleja. 
Mientras desde el sistema experto de producción de la narrativa se observa la necesidad de la inclusión de fragmentos de ese tipo para poder revelar sentidos profundos de la violencia, la mirada local que accede al informe los interpreta como violadores de lo que aquí hemos llamado la relación complementaria propia del relato. Desde esta última perspectiva, el problema es que, frente a lo que se interpreta como un abuso narrativo, no hay forma de tomar medidas para realinear el texto. Al estar fijo allí, los locales lo interpretan como una "cosa rara", algo "falso", "literatura" que injustamente se sitúa al lado de sus propios relatos.

Lo que existe, en términos generales, es una separación entre formas de conocimiento y apropiación de la memoria. Es por esto que decimos que se trata de una distancia epistemológica, nacida de los propósitos y dinámicas diferentes que tienen las memorias cercanas y las lejanas. Las primeras se dan en un escenario de intercambio: cada uno recibe y aporta algo a la construcción del relato. En ese intercambio, el pasado incluso adquiere un nuevo sentido o se da, en el presente, una nueva comprensión de ese pasado. La memoria lejana, por su parte, pierde ese sentido de intercambio en cuanto sus condiciones de producción y el dispositivo a través del cual circula no resultan accesibles a los locales cuyas voces busca reproducir. Las disputas por la memoria tienen lugar, así, en un espacio social alejado de las voces locales que alimentan, en primer lugar, esa memoria.

\section{A MODO DE CONCLUSIÓN}

Llevar a las palabras los eventos traumáticos asociados al impacto de la violencia es una vía para que aquellos no continúen habitando el cuerpo individual y social - en tanto "una secuencia insoportable de acontecimientos absolutos" (Arendt 1973: 106) que terminarían, de esa forma, destruyendo ese cuerpo desde adentro. La experiencia inefable se vuelve aprehensible, aunque sea de forma parcial, mediante el relato de la misma. Pero ese relatarse, ese contar lo sucedido, tiene varias dimensiones y alcances. Lo que aquí hemos examinado es el camino que va del relato a la narrativa, lo que implica ir de lo cercano a lo lejano. Este tránsito es necesario para dotar de sentido global al relato, pero tal adecuación global de la narración puede hacerla extraña (incluso ininteligible) para los relatadores locales.

La creación y puesta en circulación de narrativas amplias, que doten de sentido la experiencia de la violencia y se proyecten a la sociedad en general, precisan de un conocimiento experto y de una capacidad de gestión política y económica que puede ser débil o limitada para las comunidades locales. Es por esto que las memorias cercanas requieren la intervención de actores externos institucionales que posean esa capacidad. Pero al darse dicha mediación, lo que pierden los actores de las memorias locales es la capacidad de determinar 
la forma en que su memoria será reconfigurada y conmemorada (Pelak 2015). Es por esto que el ejercicio de producción y circulación de la memoria conmemorativa lejana conlleva una paradoja necesaria, es decir, inevitable: la de representar al tiempo una ruptura y una continuidad con las voces locales de las que busca ser eco.

\section{BIBLIOGRAFÍA}

AgAmben, Giorgio, 2010, Homo Sacer: El Poder Soberano y la Nuda Vida. Valencia: Pre-Textos.

AGUSTín, San, 1984, Confesiones. México, DF: Porrúa.

ARENDT, Hannah, 1973, Men in Dark Times. Harmondsworth: Penguin.

ARENDT, Hannah, 2016, La Condición Humana. Barcelona: Paidós.

ASSMANN, Jan, 2008, "Communicative and cultural memory", in Astrid Erll y Ansgar Nünning (comps.), Cultural Memory Studies: An International and Interdisciplinary Handbook. Berlín y Nueva York: De Gruyter, 109-118.

ASSMANN, Aleida, y Linda SHORTT, 2012, "Memory and political change: introduction", in Aleida Assmann y Linda Shortt (comps.), Memory and Political Change. Nueva York: Palgrave Macmillan, 1-14.

AUGÉ, Marc, 1998, Las Formas del Olvido. Barcelona: Gedisa.

BUTLER, Judith, 2017, Cuerpos Aliados y Lucha Politica: Hacia Una Teoría Performativa de la Asamblea. Barcelona: Paidós.

CASTAÑO, Daniel, y Gabriel RUIZ, 2017, "La construcción del discurso contrainsurgente como legitimador del poder paramilitar en Colombia”, Estudios Políticos, 5: 153-174.

CNMH - CENTRO NACIONAL DE MEMORIA HISTORICA, 2014, "Ese día la violencia llegó en canoa", in CNMH, Memorias de Un Retorno: Caso de las Poblaciones Palafitas del Complejo Lagunar Ciénaga Grande de Santa Marta. Bogotá: CNMH.

CNMH - CENTRO NACIONAL DE MEMORIA HISTORICA, 2017, "Misión y visión”. Consultado en < http://www.centrodememoriahistorica.gov.co/somos-cnmh/que-es-el-centro-na cional-de-memoria-historica/mision-vision > (última consultación en febrero de 2019, ya no disponible).

COBB, Sara, 2016, Hablando de Violencia: La Política y las Poéticas Narrativas en la Resolución de Conflictos. Barcelona: Gedisa.

DIDION, Joan, 1979, The White Album. Harmondsworth: Penguin Books.

GIDDENS, Anthony, 2011, Consecuencias de la Modernidad. Madrid: Alianza Editorial.

GMH - GRUPO DE MEMORIA HISTÓRICA, 2010, Bojayá: la Guerra sin Límites. Bogotá: Ediciones Semana.

GMH - GRUPO DE MEMORIA HISTÓRICA, 2013, iBasta Ya! Colombia: Memorias de Guerra y

Dignidad. Bogotá: Imprenta Nacional.

HALBWACHS, Maurice, 2004, Los Marcos Sociales de la Memoria. Barcelona: Anthropos. 
HRW - HUMAN RIGHTS WATCH, 2018, "Informe mundial 2018 - Colombia: eventos de 2017”. Disponible en < https:/www.hrw.org/es/world-report/2018/country-chapters/31 $3305>$ (última consultación en junio 2021).

JACKSON, Michael, 2002, The Politics of Storytelling. Copenhague: Museum Tusculanum Press.

JACKSON, Michael, 2005, "West-African warscapes: storytelling events, violence and the appearance of the past", Anthropological Quarterly, 78 (2): 355-375.

JURADO, Pedro, Daniel CASTAÑO, y Gabriel RUIZ, 2018, "La memoria como relato abierto: retos políticos del trabajo de los centros de memoria y las comisiones de la verdad", Análisis Político, 31 (93): 3-19.

LACLAU, Ernesto, y Chantal MOUfFE, 2001, Hegemony and Socialist Strategy: Towards a Radical Democratic Politics. Nueva York: Verso.

LEVI, Primo, 2014, Los Hundidos y los Salvados. Barcelona: Península.

MARCUS, George, 1995, "Ethnography in/of the world system: the emergence of multi-sited ethnography”, Annual Review of Anthropology, 24: 95-1 17.

MATE, Manuel Reyes, 2003, "Auschwitz, acontecimiento fundante del pensar en Europa (o ¿puede Europa pensar de espaldas a Auschwitz?)", primera conferencia del III Seminario de Filosofía de la Fundación Juan March, 7 de abril. Disponible en $<$ http://proyectos. cchs.csic.es/sscv/sites/default/files/March l.pdf > (última consultación en junio 2021).

MOLDEN, Berthold, 2016, "Resistant pasts versus mnemonic hegemony: on the power relations of collective memory", Memory Studies, 9 (29): 125-142.

PELAK, Cynthia, 2015, "Institutionalizing counter-memories of the US civil rights movement: the national civil rights museum and the application of the interest-convergence principle", Sociological Forum, 30 (2): 305-327.

PRESIDENCIA DE LA REPÚBLICA DE COLOMBIA, decreto 4803 de 2011 , "Por el cual se establece la estructura del Centro de Memoria Histórica”, Diario Oficial, 48289 del 20 de diciembre de 2011.

RICCEUR, Paul, 2004 [1995], Tiempo y Narración I: Configuración del Tiempo en el Relato Histórico. Coyoacán y Buenos Aires: Siglo XXI.

RICCEur, Paul, 2013, La Memoria, la Historia, el Olvido. Buenos Aires: Fondo de Cultura Económica.

RUIZ, Gabriel, 2017, "Representación del Estado colombiano y construcción de ciudadanía en los márgenes”, European Review of Latin American and Caribbean Studies, 104: 5-22.

RUIZ, Gabriel, y Marije HRISTOVA, 2019, "Comisionar la memoria y la verdad en la sociedad", Colombia Internacional, 97: 3-26.

RUIZ, Gabriel, Pedro JURADO, y Daniel CATAÑO, 2020, "Distancia representacional entre la narración experta y los relatos locales: una reflexión sobre las políticas de la evidencia en el campo de la memoria en Colombia", Antípoda, Revista de Antropología y Arqueología, 41: 103-124.

RUTAS DEL CONFLICTO, s.f., Masacre de Trojas de Cataca. Disponible en < http://rutasdelco nflicto.com/interna.php? masacre $=77>$ (última consultación en junio 2021).

SCARRY, Elaine, 1985, "Injury and the structure of war", Representations, 10: 1-51.

SEMANA, 2007, "El silencio de Jorge 40". Disponible en < https://www.semana.com/on-line/ articulo/el-silencio-jorge-40/86983-3 > (última consultación en junio 2021).

SEMANA, 2019, “¿Por qué no hay democracia en Colombia? La respuesta de Petro que se volvió viral". Disponible en < https://www.semana.com/nacion/articulo/video-de-gustavo-pet 
ro-en-que-el-responde-a-si-hay-o-no-democracia-en-colombia/603859 > (última consultación en junio 2021).

SORAVJI, Cornelia, 2006, "Managing memories in post-war Sarajevo: individual, bad memories and new wars", The Journal of the Royal Anthropological Institute, 12 (1): 1-18.

TODOROV, Tzvetan, 2013, Los Abusos de la Memoria. Barcelona: Paidós.

WHITE, Geoffrey, 2000, "Histories and subjectivities", Ethos, 28 (4): 493-510.

WINNICOTT, Donald, 1974, Playing and Reality. Harmondsworth: Penguin.

Receção da versão original / Original version

$2019 / 05 / 24$

Aceitação / Accepted

$2019 / 12 / 30$

Pré-publicação online / Pre-published online

$2021 / 01 / 07$ 